\title{
A leap for the journal: Clinical and Molecular Hepatology enters a new era
}

\author{
Yoon Jun Kim \\ Editor-in-Chief, Clinical and Molecular Hepatology, Seoul, Korea
}

\section{CMH ENTERS A NEW ERA}

The journal, Clinical and Molecular Hepatology (CMH), is entering a new era of its journey. Twenty-five years ago, the journal started its journey, by publishing 10 review articles in Korean and one original article in English at year 1995. The language policy has been changed to English-only in year 2010, and the journal's title has been changed from Korean Journal of Hepatology to $\mathrm{CMH}$ in 2012. The Journal was indexed in Medline since 2002, SCOPUS since 2010, Directory of Open Access Journals (DOAJ) since 2017, and Emerging Source Citation Index (ESCI) in year 2017. This year, the Journal was indexed in the Science Citation Index Expanded (SCIE). By being indexed in the SCIE, CMH has taken another leap toward a premier journal in the field of hepatology, a home for quality research, reviews, and commentaries.

\section{CMH IS RAPIDLY GROWING AND EVOLVING}

Since 2016, journal started "epub ahead of print" to provide timely information for the readers. Study Highlights was introduced to describe key results of each accepted article. $\mathrm{CMH}$ highlights has been a way to increase attention of international readers for the published articles for each issue. Online submission system has been changed to an international online platform (https://mc04.manuscriptcentral.com/cmh), to provide more convenient access for authors and reviewers for the journal. In the following years, the journal is preparing for multimedia platform. From 2012 to 2017, there were 282 citable articles from 29 countries in $\mathrm{CMH}^{1}$. The impact factor increased from 2.1 in 2014 to 2.8 in 2017. ${ }^{1}$ It is estimated to be more than 4 in 2018. The number of submitted articles was 50 in year 2014, and has increased to 100 from 23 countries until October 31, 2019.

\section{THE REASON WHY CMH IS NEEDED}

The aim of $\mathrm{CMH}$ is to share advanced and latest knowledge, trend, and understanding of hepatobiliary diseases, to provide a wide open academic forum for active debate and discussion among clinical doctors, translational researchers, and basic scientists, and to improve public health through a multidisciplinary approach. The journal is devoted to provide relevant articles to all doctors and health professionals, whether rich or poor. In doing so, a free exchange of health information is a key element, especially in a resource limited areas. $\mathrm{CMH}$ gives priority to studies of hepatobiliary diseases in East Asia, North Asia, Southeast Asia, Central Asia, South Asia, Southwest Asia, Pacific, Africa, Central

\section{Abbreviations:}

$\mathrm{CMH}$, Clinical and Molecular Hepatology; DOAJ, Directory of Open Access Journals; ESCI, Emerging Source Citation Index; KASL, the Korean Association for the Study of the Liver; SCIE, the Science Citation Index Expanded

\section{Corresponding author : Yoon Jun Kim}

Department of Internal Medicine and Liver Research Institute, Seoul National University Hospital, 101 Daehak-ro, Jongno-gu, Seoul 03080, Korea

Tel: +82-2-2072-3081, Fax: +82-2-743-6701

E-mail:yoonjun@snu.ac.kr

https://orcid.org/0000-0001-9141-7773 
Europe, Eastern Europe, Central America, and South America. Authors can publish valuable findings with no or reasonable costs, and readers can read articles for free. Scientific publishing society is in chaos by the large number of newly emerging journals, the proliferation of the high-profile, for-profit branded publications with unrealistic and poor-quality reviews, unengaged editors and the rapid rise of preprint servers that post non-peer-reviewed manuscripts. ${ }^{2}$ The not-for-profit journals with dedicated academic editors and outstanding peer reviewers are major strength of CMH. CMH will provide a 'rallying point for the local and international exchange of information', in a not-for-profit, open access platform. CMH will keep the highest standards of publishing ethics and will guarantee the rapid and transparent decision for the submitted manuscripts. CMH welcomes high quality research and innovative studies in the field of hepatology. CMH also welcomes active discussion between readers, authors and editors through letter to the editor.

\section{CMH, MOVING FORWARD}

I would like to take this opportunity to thank many people who made this possible. A special thanks to formal editors, current and formal editorial board members, the Korean Association for the Study of the Liver (KASL) governing board members, publisher, the Journal office, the whole of the editorial team, the peer reviewers, the authors and the readers. The Journal received excellent support and we are tremendously grateful. Finally, I would like to welcome the excellent new editorial team, which will be led by Prof. Seung Up Kim (Department of Internal Medicine, Yonsei University College of Medicine, Seoul, Korea). I'm sure that the journal will continue to grow and improve to be a premier journal in the field of hepatology under his leadership.

\section{Conflicts of Interest}

The author has no conflicts to disclose.

\section{REFERENCES}

1. Huh S. Journal metrics of Clinical and Molecular Hepatology based on the Web of Science Core Collection. Clin Mol Hepatol 2018;24:137-143.

2. Kaestner KH, Pack M. A new era of CMGH. Cell Mol Gastroenterol Hepatol 2019;8:527.

3. Ana J. The role of a general medical journal. BMJ 2004;328:591. 